\title{
Occupational health and job satisfaction assessment of bus rapid transit (BRT) drivers
}

\author{
Seyed Alireza Samerei, Kayvan Aghabayk*, Alireza Soltani \\ School of Civil Engineering, College of Engineering, University of Tehran, Iran
}

\section{A R T I C L E I N F O}

\section{Keywords:}

BRT driver

Mental health

Job satisfaction

Occupational problems

\begin{abstract}
A B S T R A C T
Several studies have focused on the ergonomics of commercial and urban bus drivers; however, there exists a dearth of research on bus rapid transit (BRT) drivers. This study was conducted to investigate the factors affecting BRT drivers' mental health and satisfaction, focusing on 171 BRT drivers in Tehran, Iran. The required data were collected through two questionnaires. The classification and regression tree (CART) algorithm and hierarchical clustering (HC) were used to extract factors affecting the mental health and satisfaction of BRT drivers. The important factors affecting driver mental health included disputes with passengers, depression, body mass index, criminal behaviors of passengers, driver's retirement conditions, driver's family conditions, fatigue, and the rostering. In addition, the most important factors affecting driver satisfaction included bus repairs, the driver's seat, and the sound inside the cabin. The study offers possible practical applications for creating a counseling and psychotherapy unit and improving bus quality and repairment.
\end{abstract}

\section{Introduction}

Bus rapid transit (BRT) was implemented during the late 20th century and appeared as a major urban transportation method in the first decade of the 21st century (Deng and Nelson, 2011). A transportation system that can increase transit ridership in both developing and developed countries, BRT incorporates features such as running ways, vehicles, stations, fare collection systems, operations control systems, intelligent transportation systems (ITS), and passenger information systems (Wirasinghe et al., 2013; Levinson et al., 2002), and the driver is associated with most of them. Implementing a BRT system in developing countries such as Iran usually involves facing many barriers, whether political, technical, operational, or financial (Nguyen et al., 2019). The Tehran Bus Rapid Transit System is the first BRT system in Iran and contains nine active lines. The first line started in 2007 and expanded gradually. There are currently three bus models operating on Tehran's high-speed lines, including the Newman with more than 10 years of operation, the King Long model with more than 5 years of operation, and the Utang with approximately 3 years of operation. BRT routes in Tehran service separately and in combination with the traffic of other passing cars.

Empirical evidence gathered during the last 50 years shows that in comparison with other profession groups, business or professional drivers in general are at a higher risk for developing physical and mental health problems because of accidents and business conditions. Among the risky diseases for bus drivers are cardiovascular illnesses, skeletal muscle problems, digestive issues, obesity, and high blood pressure, as well as problems such as anxiety, depression, and post-traumatic stress disorder (Greiner et al., 1998; Kompier and Di Martino, 1995; Kompier, 1996; Tse et al., 2006, 2007). In a study by Jones et al. (2014), drivers in the United Kingdom transport agency were shown to enjoy less professional quality than other employees in that agency. The working conditions of BRT drivers and other groups of professional drivers are similar; BRT drivers may be faced with factors leading to accidents, such as concerns over steady work, bad roads that cause unsafe driving conditions, job changes, high mental pressure, and heavy workload.

This study shows that the mental problems of drivers are associated with increases in work pressure, low support by coworkers, low reward, and more signal conflict during driving. To avoid mental health problems, interventions such as reducing demand, increasing work control, reducing the amount of entry data, simplifying signals, and reconsidering rewards should be considered (Gómez-Ortiz et al., 2018). There is scientific evidence that professional drivers comprise an occupational group that is highly exposed to stressors (Tse et al., 2006, 2007; Djindjić et al., 2013; Cendales-Ayala et al., 2017; Useche et al., 2017). Also, the lack of attention given by organizations to bus driver health in developing countries in terms of issues related to salaries and benefits and hardware satisfaction has a direct impact on driver stress

\footnotetext{
* Corresponding author.

E-mail addresses: alireza.samerei@ut.ac.ir (SA. Samerei), kayvan.aghabayk@ut.ac.ir (K Aghabayk), soltani.a@ut.ac.ir (A Soltani).
} 
levels (Batool and Yasir, 2018). Several recent studies show a relationship between stress and fatigue during work and adverse and illegal work behaviors (Siegrist and Rödel, 2006; Fida et al., 2015; Chen and Kao, 2013). Another study revealed that the behaviors of BRT drivers can be predicted by the pressure of work, lack of balance between effort and reward, and community support at work. It was also found that fatigue and the need for recovery are linked to work pressure and dangerous driving (Useche et al., 2017). Zuraida et al. (2016) found that despite the same amount of workload in different shifts of BRT drivers in Jakarta, Indonesia, fatigue levels varied between shifts and morning shifts resulted in more stress and drowsiness.

The physical and mental health of professional drivers are effective measures of their performance. Any lack of attention in this field leads to irreparable consequences; health problems may lead to serious accidents. Professional bus drivers use less advanced technology than what is available for train drivers and pilots, therefore they need more accurate health management. Age, obesity, depression, working hours, and other issues have significant effects on the self-reported health of professional bus drivers (Chung and Wong, 2011). Also, a body mass index (BMI) greater than 25 and poor sleep quality cause stress and burnout for drivers (Batool and Yasir, 2018). One study performed in the United Kingdom identified the sources of stress by focusing on mental health assessment and the satisfaction of urban bus drivers. The drivers showed lower degrees of satisfaction and mental health compared to the normal sample due to stress-inducing factors (Duffy and McGoldrick, 1990). In addition, the violent and bullying behaviors of passengers and sometimes coworkers have significant impacts on driver performance. Exposure to bullying has been negatively correlated with job satisfaction and driver responsibility (Tse et al., 2006; Glasø et al., 2011). A study by Gwon et al. (2007) of bus drivers in South Korea shows the effect of bus driver satisfaction on accident rates.

Recent studies reveal that bus drivers are at increased risk for physical illness due to work pressure (Tse et al., 2006). Bus drivers are exposed to adverse work and environmental conditions that may lead to critical health conditions requiring medical attention (Crizzle et al., 2017). According to Alperovitch-Najenson et al. (2010), low back pain in Israeli bus drivers is associated with hardware factors including inappropriate seat and back support and psychological factors including limited rest, heavy traffic in the bus lane, and ill-treatment by passengers.

Another common issue for urban bus drivers is the extent and manner of their work shift (Tse et al., 2006). According to several studies, shift work is associated with poor health, inadequate sleep, fatigue, and low job satisfaction (Härmä 2006; Puttonen et al., 2010), and shift planning plays a key role in shift issues (Sallinen and Kecklund, 2010). For example, shift work is associated with long shifts and low rest times, and a high number of working days results in sleep and health problems and dissatisfaction (Bambra et al., 2008; Knauth and Hornberger, 2003). However, integrating duty scheduling and rostering increases satisfaction (Borndörfer et al., 2017; Li et al., 2015). Silla and Gamero (2014) indicated that work time stress at the organizational level is inversely related to job satisfaction and self-reported health. Reasons given for leaving work include work-life imbalances, lack of social support, and temporary contracts (Lannoo and Verhofstadt, 2016). According to a study by Tiznado et al. (2014), drivers welcome incentives related to improving their performance and increasing customer satisfaction, and they believe that salary improvement should be the first strategy.

The impact of traffic is significant when the bus lane and regular traffic are mixed (Tse et al., 2006). A dedicated BRT bus shoulder is key to conducting bus rapid transportation in areas with no additional infrastructure space. However, the narrow shoulder width of the bus and the need to predict traffic hazards in the adjacent lane can be stressful for bus drivers and endanger driver health and safety (Ward et al., 2006; Ward et al., 2003). Adrenaline level in blood is a known indicator of stress. Drivers' adrenaline levels are higher during heavy traffic days than during light traffic days. Accurate detection and distance estimation tools have shown that driver ability during heavy traffic days was reduced compared to light traffic days. Increased driver adrenaline may reduce their accuracy and judgment (Hoseinabadi et al., 2015).

The conditions of BRT drivers differ from other urban and commercial drivers in several ways. BRT drivers operate different fleets in terms of facilities and bus size, and the characteristics of their transit routes and stations also differ. BRT buses often run faster and usually on isolated, narrow lanes. Also, due to the large size of the buses, they carry a large number of passengers. BRT stations are usually much shorter in time and space than those for city buses. Despite numerous studies on bus drivers, limited studies have been conducted on the ergonomics, satisfaction, and mental health of BRT drivers.

The main purpose of this study was to evaluate the general health and satisfaction of BRT drivers from various physical and psychological aspects and to investigate their affecting factors. In order to become acquainted with the current conditions of BRT drivers, researchers first interviewed them randomly. According to driver statements, the most important problems and dissatisfaction they face are due to insufficient income, which is lower than middle class levels. In addition, long shifts contribute to dissatisfaction among BRT drivers, as well as hardware issues with buses and other infrastructure of the Tehran BRT system. All these problems and conditions can affect driver satisfaction and mental health. Therefore, considering the sensitivity of this job, it is important to examine driver satisfaction and the probability of mental problems, the factors affecting them, and the effectiveness of each factor.

\section{Methodology}

Tehran Bus Company was selected to study the condition of BRT drivers. Initial group meetings and single-person interviews were held with a number of BRT drivers in Tehran, identifying their main problems and concerns. Parameters affecting the psychological and physical aspects of the drivers were extracted using initial interviews and past studies, and a questionnaire was prepared based on these parameters. Furthermore, in view of driver verbal statements and working conditions, researchers considered the possibility of mental illness among them. For this purpose, the General Health Questionnaire (GHQ28) standard test was performed and the relationship of all parameters involved with BRT drivers' mental health was investigated. Finally, by classifying drivers into two levels of mental health and satisfaction, the parameters affecting the mental health and satisfaction caused by working conditions were extracted using the classification and regression tree (CART) method.

\section{Participants}

Data were collected through interviews with randomly selected BRT drivers. The study sample consists of 171 Tehran BRT drivers, all of whom are male since there are no female BRT drivers in Tehran. The average age is 40.96 years with a standard deviation of 3.78 years, and the average employment record is 7.97 years with a standard deviation of 2.92 years.

\section{Measures}

The questionnaire design was based on previous studies containing psychological requirements, previous studies of hardware and the environmental ergonomics of BRT and bus drivers, and the major issues raised in the initial interviews. The items related to psychological requirements and hardware and environmental ergonomics are listed in Table 1. Based on the above-mentioned parameters, the questionnaire included multiple-choice questions to measure the occupational problems relative to the environmental, mental, physical, and other social and individual factors (first part of questionnaire) and the degree of satisfaction or dissatisfaction (second part of questionnaire). All 
Table 1

Variable description.

\begin{tabular}{|c|c|c|c|c|}
\hline Variable & Description & Used in CART & Used in HC & Questionnaire part \\
\hline Bus lane & Categorical $^{\mathrm{a}}$ & $\bullet$ & & 1 \\
\hline Education level & Categorical $^{\mathrm{b}}$ & $\bullet$ & & 1 \\
\hline Working experience & Continuous & $\bullet$ & & 1 \\
\hline BMI & Continuous & $\bullet$ & & 1 \\
\hline Number of working days per week & Categorical $^{\mathrm{c}}$ & $\bullet$ & & 1 \\
\hline Working hours in a day & Categorical $^{\mathrm{d}}$ & $\bullet$ & & 1 \\
\hline Number of unpaid leave & Ordinal $^{\mathrm{a}}$ & $\bullet$ & & 1 \\
\hline Interest in work & Ordinal $^{\mathrm{b}}$ & $\bullet$ & & 1 \\
\hline Concern about the criminal behavior of passengers & Ordinal $^{\mathrm{b}}$ & $\bullet$ & & 1 \\
\hline Concern over the presence of the beggars & Ordinal $^{\mathrm{b}}$ & $\bullet$ & & 1 \\
\hline Concern about the schedule implementation & Ordinal $^{\mathrm{b}}$ & $\bullet$ & & 1 \\
\hline Concern about being fined by the police & Ordinal $^{\mathrm{b}}$ & $\bullet$ & & 1 \\
\hline Concern about the condition of the family & Ordinal $^{\mathrm{b}}$ & $\bullet$ & & 1 \\
\hline Post-traumatic stress disorder (PTSD) & Ordinal $^{\mathrm{b}}$ & $\bullet$ & & 1 \\
\hline Dispute with passengers & Ordinal $^{\mathrm{b}}$ & $\bullet$ & & 1 \\
\hline The amount of sedative use & Ordinal $^{\mathrm{b}}$ & $\bullet$ & & 1 \\
\hline The amount of driver fatigue after work & Ordinal $^{\mathrm{b}}$ & $\bullet$ & & 1 \\
\hline The amount of stress felt in a mixed traffic flow & Ordinal $^{\mathrm{b}}$ & $\bullet$ & & 1 \\
\hline Satisfaction with the schedule & Ordinal $^{\mathrm{b}}$ & $\bullet$ & $\bullet$ & 2 \\
\hline Satisfaction with health insurance coverage & Ordinal $^{\mathrm{b}}$ & $\bullet$ & $\bullet$ & 2 \\
\hline Satisfaction with timely payment of salaries & Ordinal $^{\mathrm{b}}$ & $\bullet$ & $\bullet$ & 2 \\
\hline Satisfaction with retirement conditions & Ordinal $^{\mathrm{b}}$ & $\bullet$ & $\bullet$ & 2 \\
\hline Satisfaction with bus priority at intersections & Ordinal $^{\mathrm{b}}$ & $\bullet$ & $\bullet$ & 2 \\
\hline Satisfaction with the behavior of passengers & Ordinal $^{\mathrm{b}}$ & $\bullet$ & $\bullet$ & 2 \\
\hline Satisfaction with no entry for other vehicles to the special lane & Ordinal $^{\mathrm{b}}$ & $\bullet$ & $\bullet$ & 2 \\
\hline Dissatisfaction with the presence of vendors & Ordinal $^{\mathrm{b}}$ & $\bullet$ & $\bullet$ & 2 \\
\hline Satisfaction with rest and meal plans & Ordinal $^{\mathrm{b}}$ & $\bullet$ & $\bullet$ & 2 \\
\hline Satisfaction with police performance in accidents & Ordinal $^{\mathrm{b}}$ & $\bullet$ & $\bullet$ & 2 \\
\hline Satisfaction with terminal facilities & Ordinal $^{\mathrm{b}}$ & $\bullet$ & $\bullet$ & 2 \\
\hline Satisfaction with drivers' uniforms & Ordinal $^{\mathrm{b}}$ & $\bullet$ & $\bullet$ & 2 \\
\hline Satisfaction with the bus facilities & Ordinal $^{\mathrm{b}}$ & $\bullet$ & $\bullet$ & 2 \\
\hline Satisfaction with bus repair and maintenance & Ordinal $^{\mathrm{b}}$ & $\bullet$ & $\bullet$ & 2 \\
\hline Satisfaction with the driver's seat & Ordinal $^{\mathrm{b}}$ & $\bullet$ & $\bullet$ & 2 \\
\hline Dissatisfaction with cabin sound & Ordinal $^{\mathrm{b}}$ & $\bullet$ & $\bullet$ & 2 \\
\hline Satisfaction with station conditions & Ordinal $^{\mathrm{b}}$ & $\bullet$ & $\bullet$ & 2 \\
\hline Satisfaction with route pavement conditions & Ordinal $^{\mathrm{b}}$ & $\bullet$ & $\bullet$ & 2 \\
\hline Mental health (dependent variable) & Categorical $^{\mathrm{d}}$ & $\bullet$ & & \\
\hline Satisfaction (dependent variable) & Categorical $^{\mathrm{f}}$ & $\bullet$ & & \\
\hline
\end{tabular}

a Ordinal: $1=$ "0", $2=$ "1", $3=$ “2", $4=“>2 " ;{ }^{b}$ Ordinal: $1=$ very low, $2=$ low, $3=$ medium, $4=$ high, $5=$ too high;

a Categorical: line 1, line 2, line 3, line 4, line 5, line 7, line 8, line 9, line 10;

b Categorical: 1 = diploma, $2=$ bachelor of science, $3=$ master of science, $4=P h D$;

c Categorical: $1=5-6$ days, $2=6-7$ days; ${ }^{d}$ Categorical: $1=8-9$ h, $2=9-10$ h, $3=>10$ h;

d Categorical: 1 = healthy, $2=$ unhealthy; ${ }^{f}$ Categorical: $1=$ satisfaction, 2 = dissatisfaction.

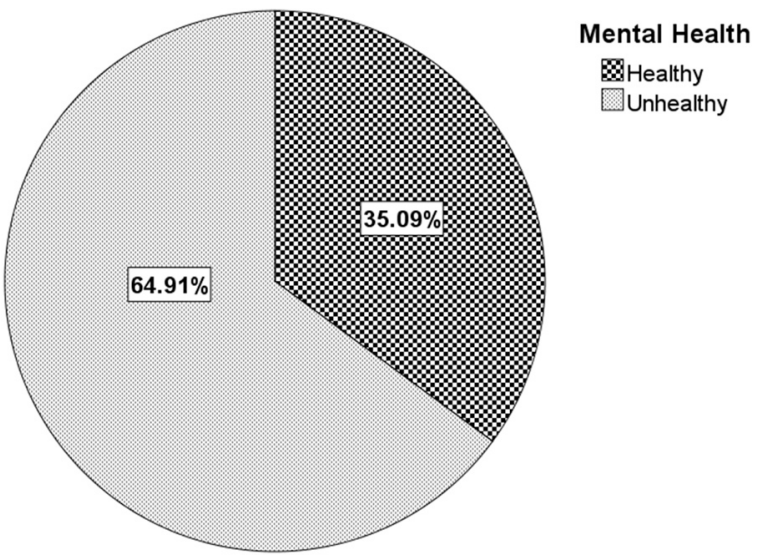

Fig. 1. Mental health ratio.

questions were sorted according to the degree of dissatisfaction or satisfaction with uniform ranking $(1=$ very low, $2=$ low, $3=$ medium, $4=$ high, $5=$ too high) and the difference between every two successive degrees was the same. The internal consistency of the scales as measured by Cronbach's alpha was 0.82 for the first part and 0.89 for the second part of questionnaire, and the questionnaires were validated by a panel of experts in the field of psychology.
To measure mental health, the General Health Questionnaire (GHQ28) (Goldberg and Hillier, 1979) was used. The GHQ-28 is a multiplechoice self-report inventory, among psychometric tests, widely used to identify minor psychiatric disorders in the general population and within the community or non-psychiatric clinical settings, such as primary care or general outpatient facilities. It contains 28 items that have been divided through factor analysis into four sub-scales (somatic symptoms, anxiety/insomnia, social dysfunction, and severe depression). The questionnaire assesses the respondent's current state and asks if that differs from his or her usual state. Respondents rate each item on a four-point Likert scale $(0=$ better/healthier than normal, $1=$ same as usual, $2=$ worse/more than usual, $3=$ much worse/more than usual). The questionnaire gives a total of $0-84$ points and Goldberg (1978) suggests that participants with scores of 23 or below should be classified as non-psychiatric, while participants with scores greater than 24 may be classified as psychiatric. Based on the obtained information, $65 \%$ of the statistical population of this study suffer from psychiatric disorders (Fig. 1). The internal consistency of the scales as measured by Cronbach's alpha was 0.91 .

Data

By collecting questionnaires completed by BRT drivers, a database of 171 rows of information was prepared. Each row contains 36 


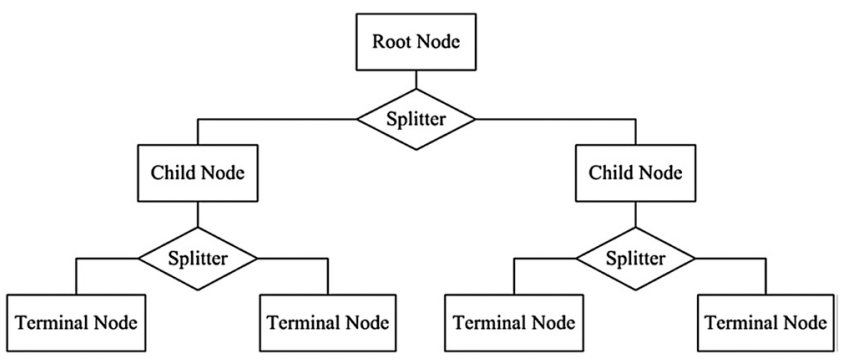

Fig. 2. Basis of decision tree.

independent parameters and Table 1 shows descriptions of each variable. Eventually 36 independent variables and 1 target variable (healthy or unhealthy) were inserted into the CART model. Also, 18 parameters, which were related to the satisfaction level of BRT drivers, were inserted into the hierarchical clustering model.

Model

Parameters affecting the possibility of mental disorders in BRT drivers were extracted by dividing them into two groups, healthy and unhealthy. For this purpose, the classification and regression tree (CART) model was used to examine the relationship between independent parameters through a questionnaire and a dependent mental health parameter. Fig. 2 depicts the basis of the CART model. The entire data are concentrated in the upper node of the tree, called the root node. The data are divided by the independent variable that produces the most purity. This process continues to the extent that each node contains data of the highest purity and is referred to as the end point or leaf.

The most popular criterion for node purity is the Gini index, which is obtained from the following equation:

$\left.\left.g(t)=\sum_{i \neq j} p(j) t\right) p(i) t\right)$

where $i$ and $j$ are categories of the target field, and:

$p(j \mid t)=\frac{p(j, t)}{p(t)}, \quad p(j, t)=\frac{\pi(j) N_{j}(t)}{N_{j}}, \quad p(t)=\sum_{j} p(j, t)$

where $\pi(j)$ is the prior probability value for category $j, N_{j}(t)$ is the number of records in category $j$ of node $t$, and $N_{j}$ is the number of records in category $j$ of the root node. Note that when the Gini index is used to find the improvement for a split during tree growth, only those records in node $t$ and the root node with valid values for the split predictor are used to compute $N_{j}(t)$ and $N_{j}$, respectively.

The hierarchical clustering (HC) algorithm was used to group BRT drivers in terms of satisfaction in different fields. HC employs two types of strategies, divisive and agglomerative. Divisive methods are "topdown" approaches in which all records start in one cluster and splits are performed recursively as one moves down the hierarchy. Agglomerative methods are "bottom-up" approaches in which each record starts in its own cluster, and pairs of clusters are merged as one moves up the hierarchy. The Ward linkage algorithm, an agglomerative method widely used in many studies (O'brien et al., 2014), was employed in the current study to group the BRT drivers. The Fig. 3 dendrogram represents the basis of the hierarchical clustering model and shows the number of clusters by defining a threshold.

The importance of the variables that intervene in the CART model is defined by variable $X$ with possible states $\left(x_{1}, x_{2}\right)$ in the following equation:

$\mathrm{VIM}=\sum_{i=1}^{h} \frac{n x_{i}}{n}\left(I\left(C \mid X=x_{i}\right)-(c)\right)$

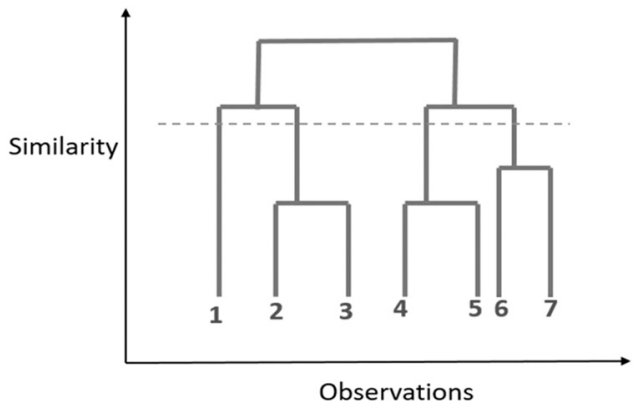

Fig. 3. Basis of the hierarchical clustering.

where $C$ is the class variable (mental or satisfaction status), $n x_{i}$ is the number of cases in which $X=x_{i}, n$ is the number of total cases, and $I$ is the Gini index.

The decision tree's structure can be transformed into rules to extract potentially useful information. Each possible path from root to leaf in the decision can be a rule and its validity can be measured by support and lift criteria. The support is the ratio between the number of items belonging to the class $j$ of the terminal node $t$ and the total number of items. The lift is the ratio between the proportion of items in the terminal node $t$ and root node that belong to the class $j$.

In this study, accuracy was measured by 10 -fold cross-validation for CART models due to the limited amount of data. Overall precision, recall, and F-score were extracted according to the classification table to rank the dependent variable as either positive or negative. Accordingly, Table 2 summarizes the four different cases.

As illustrated in Table 2, TP and TN denote the number of positive and negative samples that were accurately predicted by the model, while FP and FN indicate the number of positive and negative samples that were wrongly classified. To assess the model performance using the classification table, the following measurements should be calculated first:

Accuracy $=(\mathrm{TP}+\mathrm{TN}) /(\mathrm{P}+\mathrm{N})$

Precision $=\mathrm{TP} /(\mathrm{TP}+\mathrm{FP})$

Sensitivity or Recall $=\mathrm{TP} /(\mathrm{TP}+\mathrm{FN})$

$F_{1-\text { score }}=\frac{2 \times \text { Precision } \times \text { Recall }}{\text { Precision }+ \text { Recall }}$

Eq. (4) can be used to obtain the model's overall accuracy. The closer the model is to 1 in accuracy, the stronger it is in classifying the samples. Eq. (5) can be used to obtain the model's precision, and it is the ratio of correctly predicted positive observations to the total predicted positive observations, which demonstrates the accuracy of the model. High precision relates to low false positive rate. Eq. (6) can be used to obtain the model's recall, and it is the ratio of correctly predicted positive observations to all observations in an actual class, which shows the sensitivity of the model. Eq. (7) can be used to obtain the model's $F_{1-\text { score }}$,which might be a better measure to use if a balance is needed between precision and recall, especially when choosing the best depth of the decision tree.

Table 2

Confusion Matrix.

\begin{tabular}{lll}
\hline \multirow{2}{*}{ Observed } & Predicted & \\
\cline { 2 - 3 } & Positive & Negative \\
\hline Positive & TP & FN \\
Negative & FP & TN \\
Total & P & N \\
\hline
\end{tabular}

$\mathrm{FN}=$ false negative; $\mathrm{FP}=$ false positive;

$T N=$ true negative; $T P=$ true positive. 
Table 3

Confusion matrix and accuracy of mental health model.

\begin{tabular}{|c|c|c|c|c|c|c|}
\hline \multirow[t]{2}{*}{ Observed } & \multicolumn{2}{|c|}{ Predicted } & \multirow[t]{2}{*}{ Accuracy } & \multirow[t]{2}{*}{ Precision } & \multirow[t]{2}{*}{ Recall } & \multirow[t]{2}{*}{ F1 Score } \\
\hline & Positive & Negative & & & & \\
\hline Positive & 48 & 12 & $80.0 \%$ & $82 \%$ & $80 \%$ & 0.81 \\
\hline Negative & 10 & 101 & $91.0 \%$ & & & \\
\hline Overall percentage & $33.9 \%$ & $66.1 \%$ & $87.1 \%$ & & & \\
\hline
\end{tabular}

\section{Results}

\section{Mental health model}

The CART method was used to implement the decision tree, analyzing and classifying BRT drivers into the two categories of healthy mental and unhealthy mental. Modelers often face the issue of overfitting data, which leads to a high precision rate but does not work well in the evaluation process. One way to prevent overfitting in decision trees is to prune, controlling and preventing an increase in the depth of the tree. One parameter is the F1 score controller, which if maximized represents the balance between the precision and recall of the model and reduces the problem of overfitting. The six-step expansion depth of the decision tree was selected for this study, with multiple modeling and different depths, accuracy, and the F1 score.

Using a 10-fold cross-validation method, the prediction model of mental health probability was developed 10 times and evaluated. The mean accuracy of the model is $81.7 \%$, which is appropriate. Table 3

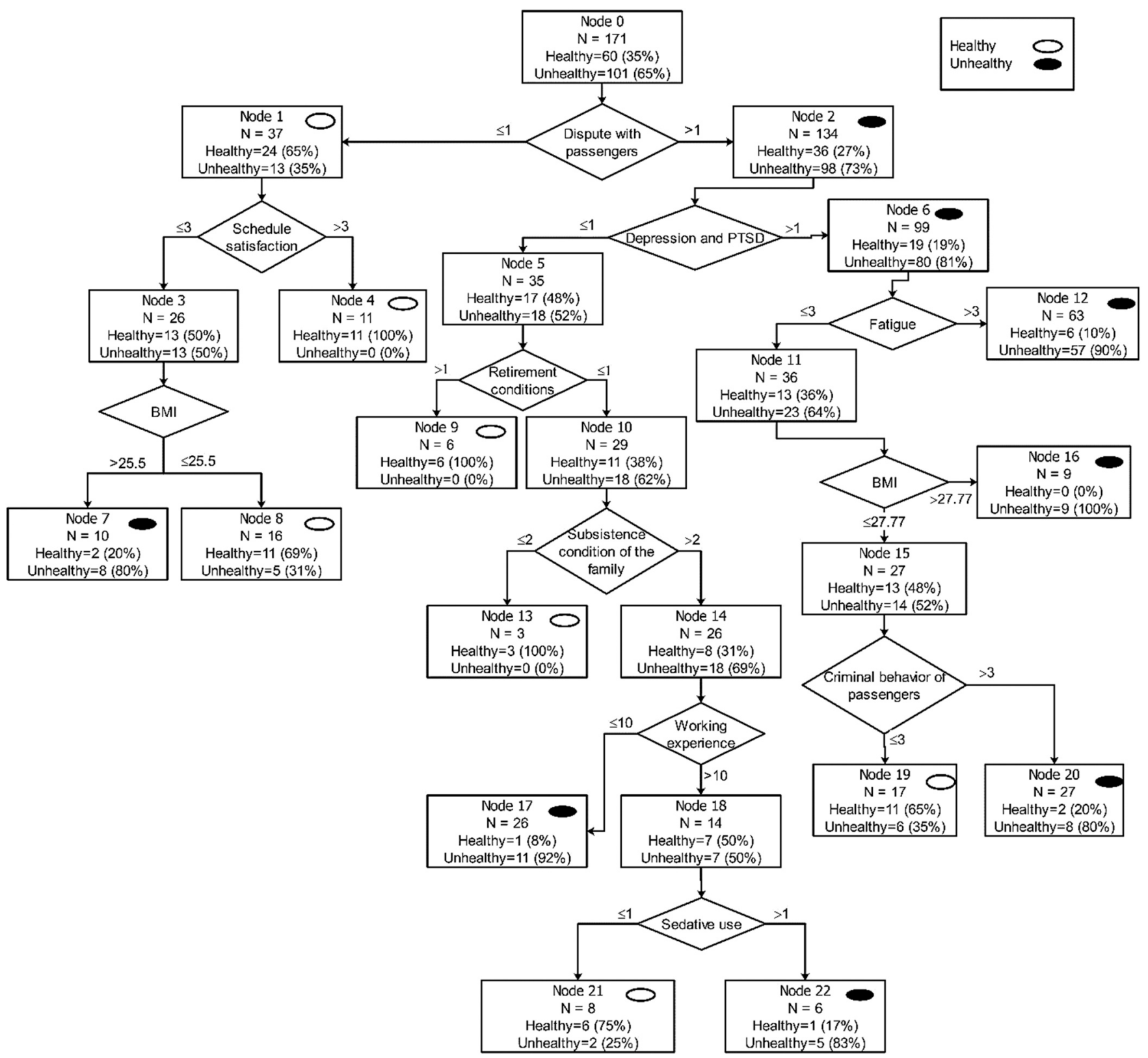

Fig. 4. Decision tree of mental health model. 
lists the evaluation of each step and the final confusion matrix of all the steps. The accuracy of diagnosis for healthy mental and unhealthy mental is $80 \%$ and $91 \%$, respectively, and the model's evaluation shows that the input parameters are capable of detecting healthy and unhealthy BRT drivers.

\section{Structure of mental health model}

Fig. 4 displays the decision tree used for this study, which consists of 23 nodes and 12 leaves. The root node data are divided into two categories based on dispute with passengers. Drivers with a mental disorder rate greater than 1 are more likely to suffer a mental disorder than those with a rate equal to or less than 1 (70\% vs. 35\%). Among BRT drivers with a passenger dispute rate greater than 1 (node 2), postaccident depression is an effective parameter of driver separation. A BRT driver with a depression rate of more than 1 is $80 \%$ likely to suffer a mental disorder. Continuing from the previous section (node 6), the determinant factor is fatigue, and the driver with a fatigue rate higher than 3 is $90 \%$ likely to suffer a mental disorder. The only effective physical parameter is the body mass index (BMI) of the driver (node 11). Drivers with a BMI greater than 27.7 , which is considered overweight, are $100 \%$ likely to have a mental disorder. On the other hand, among drivers with a normal BMI, the parameter of concern about passenger criminal behavior (node 15) is the determining factor for mental health. The likelihood of mental disorder with a concern rate higher than 1 about passenger criminal behavior is $80 \%$.

Drivers with a history of depression rate less than 2 (node 5) and a retirement satisfaction rate more than 1 enjoy mental health (node 9). Among those with a retirement satisfaction rate less than 2, concern about family status is the determining factor (node 10). BRT drivers not worried about family status are $100 \%$ likely to enjoy mental health (node 13). The next determining parameter is the driver record. It is noteworthy that drivers with less than 10 years of work experience have a $92 \%$ possibility of suffering a mental disorder. Among drivers with a long work history, use of sedatives is the separating factor (node 18). Drivers with sedative drug experience are $84 \%$ more likely to suffer a mental disorder.

Among drivers who are less likely to argue with passengers, a satisfaction with schedule rate greater than 3 improves their mental health (node 4). For drivers dissatisfied with the schedule, the BMI parameter differentiates and those with better physical health (BMI $<25.5$ ) are classified in the mental health group.

\section{Satisfaction model}

The clustering method was used to study the factors affecting satisfaction and classification of BRT drivers. In this way, BRT drivers with the same level of satisfaction are within one cluster and are separated from others. By defining a threshold in the dendrogram shown in Fig. 5, the desired number of clusters can be defined. Two general clusters are defined under the rubric of desirable satisfaction (cluster 1) and undesirable satisfaction (cluster 2). Accordingly, each BRT driver is labeled as either cluster 1 or cluster 2 .

To find the effective factors on this clustering, decision tree modeling was used. In the decision tree, satisfaction variables were defined as inputs and cluster labels as dependent variables.

Using a 10 -fold cross-validation method, the satisfaction predictive model was developed and evaluated 10 times. The mean accuracy of the model is $87.8 \%$, which is appropriate. Table 4 displays the evaluation of the final confusion matrix of all the steps. The accuracy of satisfaction and dissatisfaction in this model is $91.5 \%$ and $81.5 \%$, respectively. The evaluation shows that input parameters of the model have the ability to predict cluster 1 and cluster 2 .

\section{Structure of satisfaction model}

The overall view of the tree structure shown in Fig. 6 reveals the significant hardware parameters of this model. The first separating parameter at the root node is the driver's satisfaction with the seat. If the driver satisfaction rate is greater than 1 , there is a probability of $81.6 \%$ that the driver will be grouped in the satisfaction category (node 2). Drivers with relative satisfaction of the driver's seat are separated by the parameter of satisfaction over bus repairs. Drivers who have the least satisfaction with repairs are $75 \%$ likely to have no job satisfaction (node 5). Among drivers with a satisfaction rate less than or equal to 1 for the seat conditions, the next determining parameter is noise pollution control outside the bus. If the rate of a driver suffering from noise pollution is greater than 3 , he is $88.6 \%$ likely to be unsatisfied (node 4); otherwise, the drivers' satisfaction with bus priority at intersections over other traffic flows will be affecting. If a driver's relative satisfaction with intersection conditions rates higher than 1 , the driver will certainly have job satisfaction.

\section{Rules extraction}

Each of the paths leading to the tree leaves can be a rule. Measuring the ability to rely on these rules is important. In this study, these standards were measured using support and lift criteria: the support threshold was set to $30 \%$, confidence to $80 \%$, and lift to 1.4 .

The sole and most important rule of the mental health model for BRT drivers is related to the route leading to node 12 . Drivers with a rate of dispute with passengers, depression, and fatigue more than 1,1 , and 2 , respectively, are highly exposed to mental problems.

Two rules apply to the satisfaction model: (1) Drivers with seat and repairs satisfaction rates greater than 1 have higher job satisfaction, and

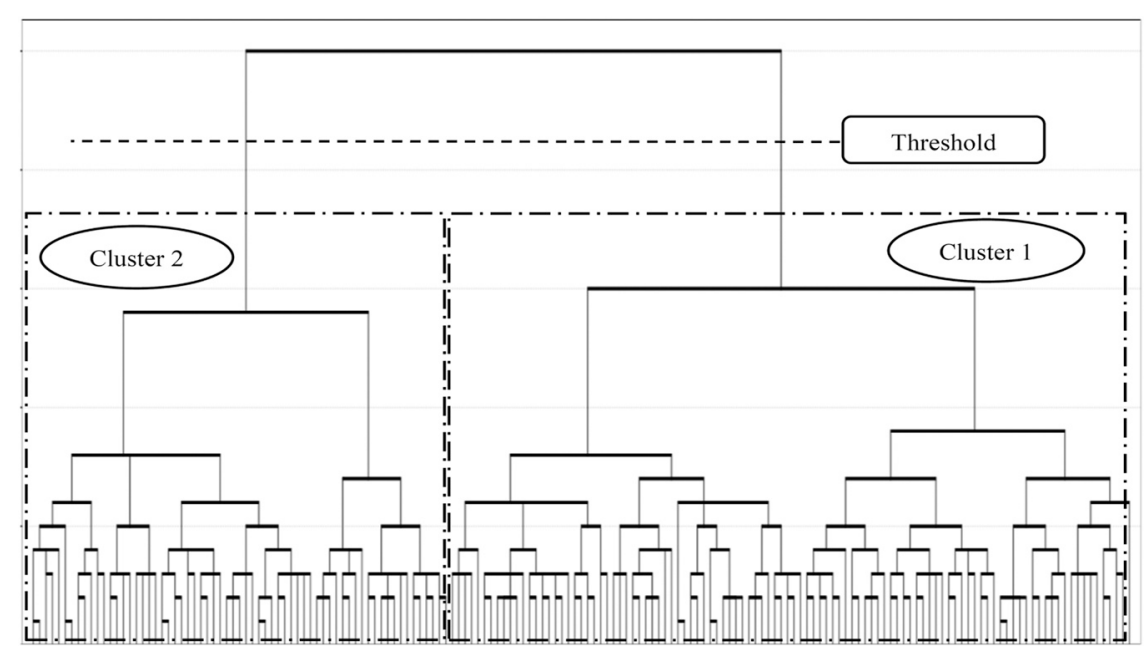

Fig. 5. Hierarchical clustering of satisfaction. 
Table 4

Confusion matrix and accuracy of satisfaction model.

\begin{tabular}{|c|c|c|c|c|c|c|}
\hline \multirow[t]{2}{*}{ Observed } & \multicolumn{2}{|c|}{ Predicted } & \multirow[t]{2}{*}{ Accuracy } & \multirow[t]{2}{*}{ Precision } & \multirow[t]{2}{*}{ Recall } & \multirow[t]{2}{*}{ F1 Score } \\
\hline & Positive & Negative & & & & \\
\hline Positive & 97 & 9 & $91.5 \%$ & 0.88 & 0.91 & 0.89 \\
\hline Negative & 12 & 53 & $81.5 \%$ & & & \\
\hline Overall Percentage & $63.7 \%$ & $36.3 \%$ & $87.8 \%$ & & & \\
\hline
\end{tabular}

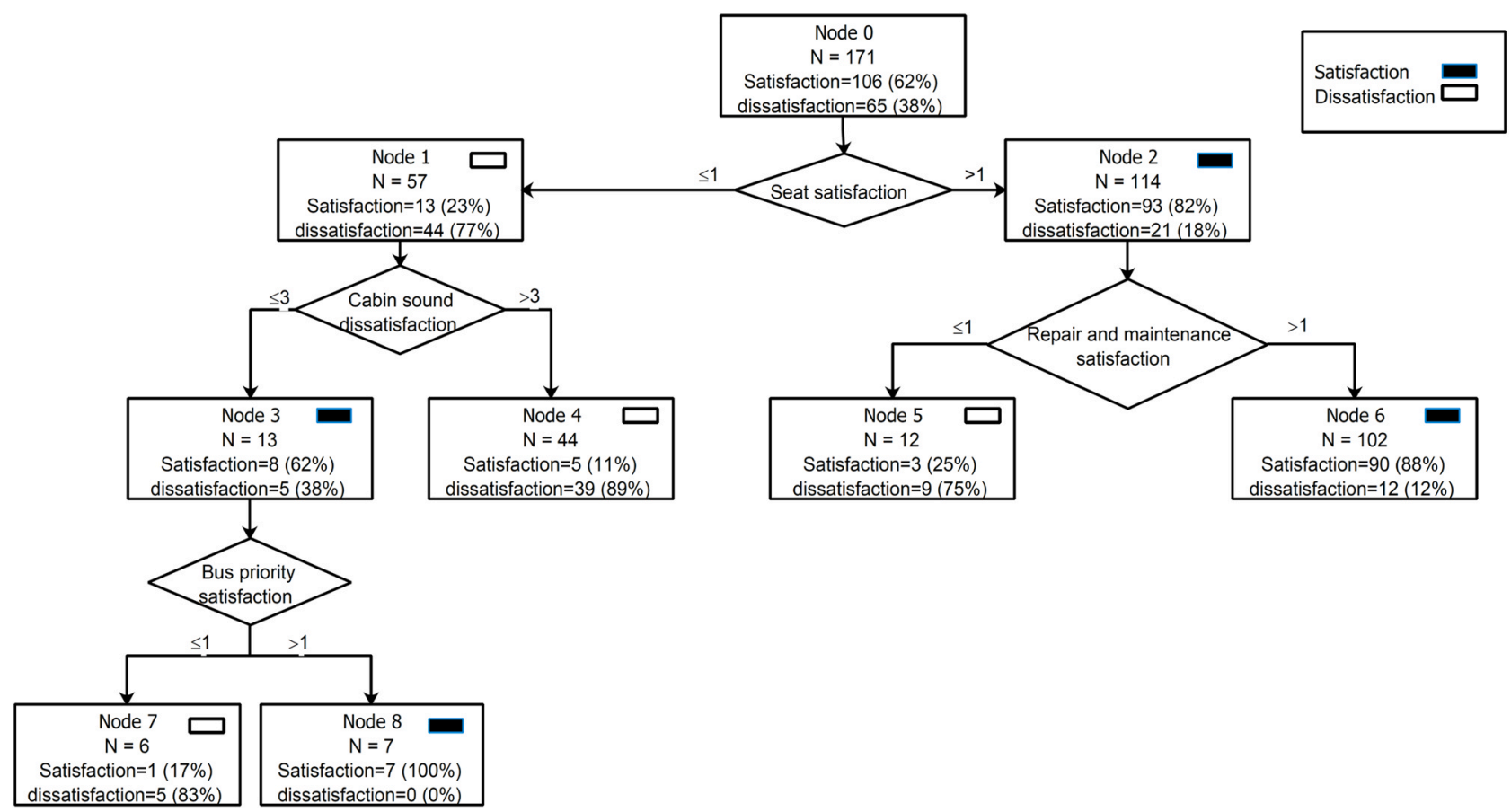

Fig. 6. Decision tree of satisfaction model.

Table 5

Most important rules.

\begin{tabular}{|c|c|c|c|c|c|}
\hline Node & Rules: IF.... & Then & Support & Confidence & Lift \\
\hline 12 & IF(dispute with passengers $>1$ ) AND (depression $>1$ ) AND (fatigue $>2$ ) & Unhealthy & $\frac{57}{171}=33 \%$ & $\frac{57}{63}=90 \%$ & $\frac{57}{63} / \frac{111}{171}=1.4$ \\
\hline 6 & IF(seat satisfaction > 1) AND (repairs satisfaction > 1) & Satisfaction & $\frac{90}{171}=52 \%$ & $\frac{90}{102}=88 \%$ & $\frac{90}{102} / \frac{106}{171}=1.41$ \\
\hline 4 & $\mathrm{IF}$ (with seat satisfaction $\leq 1$ ) AND (noise dissatisfaction $>1$ ) & Dissatisfaction & $\frac{39}{171}=22 \%$ & $\frac{39}{44}=88 \%$ & $\frac{39}{44} / \frac{65}{171}=2.3$ \\
\hline
\end{tabular}

(2) Drivers with seat satisfaction rates less than or equal to 1 and noise dissatisfaction inside the cabin at rates above 3 are more likely to be dissatisfied. Table 5 lists valid rules for predicting the likelihood of a BRT driver's mental health and job satisfaction.

\section{Discussion}

\section{Mental health}

One of the advantages of CART models is the ability to detect important and effective parameters in predicting the model input labels. The importance of each parameter depends on the ability of that parameter to purify the data. The significance of the important parameters of the mental health of BRT drivers' model was estimated using Eq. (3). Each variable was normalized and sorted, and Table 6 lists the variables in order of importance. Parameters with little importance were removed from the table.

Dispute with passengers is the first and most important parameter affecting a driver's mental health, with $100 \%$ importance. Due to the internal structure of the buses and the absence of driver seat isolation, it is possible for passengers to converse with the driver. Most reports also suggest that passengers talk to drivers about the stop time at crowded stations, often discussing problems getting off and on buses. According to other studies, aggressive behaviors with drivers negatively affect their job satisfaction (Glasø et al., 2011).

Depression is the second most important parameter affecting driver mental health, with $77.8 \%$ importance. A common mental disorder in society, depression can be easily detected. It is also predicted that a history of depression will affect driver health. Body mass index has $76.7 \%$ importance as a factor affecting mental health, indicating that fitness impacts mental health or vice versa. Chung and Wong (2011) also highlighted the impact of depression and BMI on drivers' self-reported health, while Batool and Yasir (2018) reported that a BMI greater than 25 causes driver stress and burnout.

Concerns about the criminal behavior of passengers are significant at $56.2 \%$. Due to the driver's responsibility regarding passengers along the route, stress over criminal behavior by passengers is inevitable. This feeling affects driver health and may lead to misbehavior (Chen and 
Table 6

Variable significance of mental health model.

\begin{tabular}{|c|c|c|c|}
\hline Variables & $\begin{array}{l}\text { Normalized } \\
\text { importance } \\
(\%)\end{array}$ & Variables & $\begin{array}{l}\text { Normalized } \\
\text { importance } \\
(\%)\end{array}$ \\
\hline Dispute with passengers & 100 & Concern about the subsistence condition of the family & 46.9 \\
\hline Depression and PTSD & 77.8 & The amount of driver fatigue after work & 44.8 \\
\hline BMI & 76.7 & Satisfaction with the schedule & 44.6 \\
\hline Concern about the criminal behavior of passengers & 56.2 & The amount of sedative use & 36.3 \\
\hline Satisfaction with retirement conditions & 50.7 & Working experience & 19.5 \\
\hline
\end{tabular}

Kao, 2013).

Due to the specific economic conditions of Iran, financial concerns of drivers currently employed and after retirement produce immediate and long-term stress and anxiety that can affect their mental health. The study found $50.7 \%$ importance for driver satisfaction with retirement and $46.9 \%$ importance for driver concern about family status. Chen and Hsu (2020) found in their study of Taiwanese bus drivers that workfamily conflict is stressful for drivers, but that organizational support can reduce driver stress.

Fatigue has always been an issue for shift jobs, including urban bus driving (Härmä 2006). According to several studies, fatigue leads to making mistakes (Gastaldi et al., 2014), physical discomfort (Useche et al., 2017), especially for BRT drivers, a reduced safety level, and results in more stress and drowsiness (Zuraida et al., 2016). The negative impact of long-term shifts on health and satisfaction has also been emphasized. Bambra et al. (2008) reported BRT driver fatigue as having an importance degree of $44.8 \%$ and schedule satisfaction having an importance degree of $44.7 \%$ in affecting mental health. However, proper and integrating duty scheduling increase driver satisfaction (Borndörfer et al., 2017; Li et al., 2015).

Other less important parameters include work experience and the use of sedatives. These parameters are placed as the next priorities in case required.

\section{Satisfaction}

The significance of the model's important parameters for predicting the level of BRT driver satisfaction was estimated using Eq. (3). Each variable was normalized and sorted, and Table 7 lists the variables in order of importance.

Although BRT driver satisfaction with bus repair is not the first determining parameter on the decision tree, it is the most important parameter affecting job satisfaction, with $100 \%$ importance. The quality of bus repairs has been less considered in studies and is not usually cited as a driver satisfaction factor, but for this study, it is a hidden and highly influential factor in satisfaction level.

The second most effective parameter, with $83 \%$ importance, is driver seat satisfaction. Previous studies have also emphasized the effect of an inappropriate seat on physical discomfort such as low back pain (Alperovitch-Najenson et al., 2010). Due to the high importance of this parameter and the convenience and low cost of upgrading it, driver satisfaction can be quickly increased. Another hardware parameter

Table 7

Variable significance of satisfaction model.

\begin{tabular}{clll}
\hline Variables & $\begin{array}{l}\text { Normalized } \\
\text { importance } \\
(\%)\end{array}$ & Variables & $\begin{array}{l}\text { Normalized } \\
\text { importance } \\
\text { (\%) }\end{array}$ \\
\hline $\begin{array}{c}\text { Satisfaction with } \\
\text { bus repair and } \\
\text { maintenance }\end{array}$ & 100 & $\begin{array}{l}\text { Dissatisfaction } \\
\text { with cabin sound }\end{array}$ & 77.1 \\
$\begin{array}{c}\text { Satisfaction with } \\
\text { the driver's } \\
\text { seat }\end{array}$ & 83 & $\begin{array}{l}\text { Satisfaction with } \\
\text { bus priority at } \\
\text { intersections }\end{array}$ & 16.6 \\
\hline
\end{tabular}

affecting driver job satisfaction, with $77.1 \%$ importance, is noise in the cabin. Usually, the lack of isolation of the driver's cabin against the noise coming from inside and outside the bus, especially during traffic congestion, causes the driver to become more tired and therefore less satisfied.

\section{Conclusions}

Regarding the effects of satisfaction and mental health of the staff of a transportation complex on function and level of safety, rapid diagnosis of dissatisfaction and possible mental illness is important. The findings of this study determined that exposure to some psychological, physical, and dissatisfaction factors significantly increase the likelihood of mental disorder in BRT drivers. These factors include disputes with passengers, a driver's depression history, body mass index, concern for passenger criminal behavior, satisfaction with retirement conditions, concern about family status, fatigue, satisfaction with scheduling, work experience, and sedative use. Bus doors can be fully mechanized, eliminating this task for the driver, to relieve tensions and disputes between drivers and passengers. The doors should be automatically opened and closed according to the rate of demand for passengers arriving at the station, bus capacity, stop time limit, and passenger safety. Also, wider and separate doors for boarding and alighting facilitate and expedite passenger movements (Zimmerman and Levinson, 2004; Diaz and Schneck, 2000). Depression can be easily diagnosed with valid tests such as the Beck Depression Inventory, and then quickly addressed through counseling and psychotherapy sessions. Due to the prolonged sitting associated with driving and the consequent fatigue, inadequate movement often leads to inappropriate BMI, which can be partially offset by planning general in-house sports. The best solution for concern about the criminal behavior of passengers is to provide drivers quick communication with security forces in times of danger. There is still extensive debate at the national level regarding retirement satisfaction and concerns about family situations, but these issues could be resolved to a large extent by offering optimal in-house management and contracts with appropriate insurance and service organizations. Running correct and sometimes innovative timing programs (Ihlström et al., 2017; Ceder et al., 2013) and measuring them can greatly reduce driver fatigue and increase satisfaction.

The performance and safety level of a transportation complex depends on employee performance and is affected by their dissatisfaction. Many issues leading to dissatisfaction can be identified and resolved, but there are also hidden and influential factors. According to this study, the most important parameter affecting the satisfaction of BRT drivers involves hardware issues. Improving the quality of repairs as well as the quality and safety of buses will improve job satisfaction for drivers. Also, isolating the driver's cab to reduce noise pollution and using up-to-date seats suitable for drivers will significantly impact satisfaction, and a suitable driver's seat will reduce muscle problems and back pain (Alperovitch-Najenson et al., 2010). In addition, BRT drivers can benefit from navigation and warning systems to assist them on narrow roads (Ward et al., 2003).

Bus quality-the most important parameter affecting job satisfaction for BRT drivers - can be easily controlled and planned for. Despite 
the existence and activity of several BRT fleets in Tehran, it is possible to determine the best type of bus and the reasons for its suitability by asking drivers, and to include those buses in long-range planning. Increasing the quality of drivers' dining and rest areas, stabilizing employment, creating fair policies, improving the overall well-being of employees, and increasing salaries and benefits will also be helpful (Gwon et al., 2007). In order to assess the mental health status and satisfaction of drivers in other similar organizations, the decision trees presented in this study can be used. Also, according to the specific conditions of other organizations or cities, appropriate questionnaires can be prepared and administered as defined by the framework presented here.

\section{Limitations}

After reviewing previous studies in this field, the available data, and conducting initial interviews with a number of BRT drivers in Tehran, the authors tried to discover parameters that might affect the problems and dissatisfaction of drivers in different areas and to measure them in a questionnaire. Due to the limited sample and initial observations, some of the effective and hidden parameters on mental health and satisfaction were excluded. Also, the limited sample size studied had a small effect on grouping and effective parameters, for which low-sensitivity models were used. Finally, considering the special cultural and economic conditions of Tehran, the results and models of this study should be used and exploited with caution.

\section{Declaration of Competing Interest}

The authors declare that they have no known competing financial interests or personal relationships that could have appeared to influence the work reported in this paper.

\section{Acknowledgments}

The authors thank the Tehran Bus Transit Company for arranging interviews with bus drivers and cooperating in the collection and completion of the questionnaires.

\section{References}

Alperovitch-Najenson, D., Santo, Y., Masharawi, Y., Katz-Leurer, M., Ushvaev, D., Kalichman, L., 2010. Low back pain among professional bus drivers: ergonomic and occupational-psychosocial risk factors. Isr. Med. Assoc. J. 12 (1), 26-31.

Bambra, C.L., Whitehead, M.M., Sowden, A.J., Akers, J., Petticrew, M.P., 2008. Shifting schedules: the health effects of reorganizing shift work. Am. J. Prev. Med. 34 (5), 427-434. https://doi.org/10.1016/j.amepre.2007.12.023

Batool, Z., Yasir, A., 2018. The influence of sleep quality, safety culture and cabin ergonomics on work-related stress and burnout of bus drivers in Lahore. J. Transp. Health 9, S24-S25. https://doi.org/10.1016/j.jth.2018.05.081

Borndörfer, R., Schulz, C., Seidl, S., Weider, S., 2017. Integration of duty scheduling and rostering to increase driver satisfaction. Public Transp. 9 (1-2), 177-191. https://doi. org/10.1007/s12469-017-0153-3

Ceder, A., Hassold, S., Dunlop, C., Chen, I., 2013. Improving urban public transport service using new timetabling strategies with different vehicle sizes. Int. J. Urban Sci. 17 (2), 239-258. https://doi.org/10.1080/12265934.2013.776287

Cendales-Ayala, B., Useche, S.A., Gómez-Ortiz, V., Bocarejo, J.P., 2017. Bus operators' responses to job strain: an experimental test of the job demand-control model. J. Occup. Health Psychol. 22 (4), 518-527. https://doi.org/10.1037/ocp0000040

Chen, C.-F., Hsu, Y.-C., 2020. Taking a closer look at bus driver emotional exhaustion and well-being: evidence from taiwanese urban bus drivers. Saf. Health Work 11 (3), 353-360. https://doi.org/10.1016/j.shaw.2020.06.002

Chen, C.-F., Kao, Y.-L., 2013. The connection between the hassles-burnout relationship, as moderated by coping, and aberrant behaviors and health problems among bus drivers. Accid. Anal. Prev. 53, 105-115. https://doi.org/10.1016/j.aap.2013.01.004

Chung, Y.-S., Wong, J.-T., 2011. Developing effective professional bus driver health programs: an investigation of self-rated health. Accid. Anal. Prev. 43 (6), 2093-2103. https://doi.org/10.1016/j.aap.2011.05.032

Crizzle, A.M., Bigelow, P., Adams, D., Gooderham, S., Myers, A.M., Thiffault, P., 2017. Health and wellness of long-haul truck and bus drivers: a systematic literature review and directions for future research. J. Transp. Health 7 (Part A), 90-109. https://doi. org/10.1016/j.jth.2017.05.359

Deng, T., Nelson, J.D., 2011. Recent developments in bus rapid transit: a review of the literature. Transp. Rev. 31 (1), 69-96. https://doi.org/10.1080/01441647.2010.
492455

Diaz, R.B., Schneck, D.C., 2000. Bus rapid transit technologies in the Americas: an overview. Transp. Res. Rec. J. Transp. Res. Board 1731 (1), 3-9. https://doi.org/10. 3141/1731-01

Djindjić, N., Jovanović, J., Djindjić, B., Jovanović, M., Pešić, M., Jovanović, J.J., 2013. Work stress related lipid disorders and arterial hypertension in professional drivers: a cross-sectional study. Vojnosanitetski Pregled 70 (6), 561-568. https://doi.org/10. 2298/VSP1306561D

Duffy, C.A., McGoldrick, A.E., 1990. Stress and the bus driver in the UK transport industry. Work Stress 4 (1), 17-27. https://doi.org/10.1080/02678379008256961

Fida, R., Paciello, M., Tramontano, C., Fontaine, R.G., Barbaranelli, C., Farnese, M.L., 2015. An integrative approach to understanding counterproductive work behavior: the roles of stressors, negative emotions and moral disengagement. J. Bus. Eth. 130 (1), 131-144. https://doi.org/10.1007/s10551-014-2209-5

Gastaldi, M., Rossi, R., Gecchele, G., 2014. Effects of driver task-related fatigue on driving performance. Procedia - Soc. Behav. Sci. 111, 955-964. https://doi.org/10.1016/j. sbspro.2014.01.130

Glasø, L., Bele, E., Nielsen, M.B., Einarsen, S., 2011. Bus drivers' exposure to bullying at work: an occupation-specific approach. Scand. J. Psychol. 52 (5), 484-493. https:// doi.org/10.1111/j.1467-9450.2011.00895.x

Goldberg, D., 1978. Manual of the General Health Questionnaire. NFER, Windsor.

Goldberg, D.P., Hillier, V.F., 1979. A scaled version of the general health questionnaire. Psychol. Med. 9 (1), 139-145. https://doi.org/10.1017/s0033291700021644

Gómez-Ortiz, V., Cendales, B., Useche, S., Bocarejo, J.P., 2018. Relationships of working conditions, health problems and vehicle accidents in bus rapid transit (BRT) drivers. Am. J. Ind. Med. 61 (4), 336-343. https://doi.org/10.1002/ajim.22821

Greiner, B.A., Krause, N., Ragland, D.R., Fisher, J.M., 1998. Objective stress factors, accidents, and absenteeism in transit operators: a theoretical framework and empirical evidence. J. Occup. Health Psychol. 3 (2), 130-146. https://doi.org/10.1037//10768998.3.2.130

Gwon, Y.-S., Kim, J.-S., Park, J.-S., Lee, C., 2007. A casual correlative analysis of bus driver job satisfaction on passenger service performance. J. Korean Soc. Transp. 25 (1), 93-105.

Härmä, M., 2006. Workhours in relation to work stress, recovery and health. Scand. J. Work, Environ. Health 32 (6), 502-514. https://doi.org/10.5271/sjweh.1055

Hoseinabadi, S., Porabdeyan, S., Zare, M., Amiri, S., Ghasemi, M., Mansori, A., 2015. Does traffic stress affect distance estimation and recognition accuracy in urban bus drivers? Arch. Environ. Occup. Health 70 (4), 214-217. https://doi.org/10.1080/19338244. 2013.859121

Ihlström, J., Kecklund, G., Anund, A., 2017. Split-shift work in relation to stress, health and psychosocial work factors among bus drivers. Work 56 (4), 531-538. https://doi. org/10.3233/WOR-172520

Jones, W., Haslam, R., Haslam, C., 2014. Measuring job quality: a study with bus drivers. Appl. Ergon. 45 (6), 1641-1648. https://doi.org/10.1016/j.apergo.2014.05.015

Knauth, P., Hornberger, S., 2003. Preventive and compensatory measures for shift workers. Occup. Med. 53 (2), 109-116. https://doi.org/10.1093/occmed/kqg049

Kompier, M.A.J., 1996. Bus Drivers: Occupational Stress and Stress Prevention. International Labour Office, Geneva.

Kompier, M.A.J., Di Martino, V., 1995. Review of bus drivers' occupational stress and stress prevention. Stress Med. 11 (1), 253-262. https://doi.org/10.1002/SMI. 2460110141

Lannoo, S., Verhofstadt, E., 2016. What drives the drivers? Predicting turnover intentions in the belgian bus and coach industry. Transp. Res. Part A: Policy Pract. 91, 251-259. https://doi.org/10.1016/j.tra.2016.06.024

Levinson, H.S., Zimmerman, S., Clinger, J., Rutherford, G.S., 2002. Bus rapid transit: an overview. J. Public Transp. 5 (2), 1-30. https://doi.org/10.5038/2375-0901.5.2.1

Li, H., Wang, Y., Li, S., Li, S., 2015. A column generation based hyper-heuristic to the bus driver scheduling problem. Discr. Dyn. Nat. Soc. 2015 (2), 1-10. https://doi.org/10. $1155 / 2015 / 638104$

Nguyen, M.H., Ha, T.T., Tu, S.S., Nguyen, T.C., 2019. Impediments to the bus rapid transit implementation in developing countries - a typical evidence from Hanoi. Int. J. Urban Sci. 23 (4), 464-483. https://doi.org/10.1080/12265934.2019.1577747

O'brien, O., Cheshire, J., Batty, M., 2014. Mining bicycle sharing data for generating insights into sustainable transport systems. J. Transp. Geogr. 34, 262-273. https:// doi.org/10.1016/j.jtrangeo.2013.06.007

Puttonen, S., Härmä, M., Hublin, C., 2010. Shift work and cardiovascular disease pathways from circadian stress to morbidity. Scand. J. Work, Environ. Health 36 (2), 96-108. https://doi.org/10.2307/40967836

Sallinen, M., Kecklund, G., 2010. Shift work, sleep, and sleepiness - differences between shift schedules and systems. Scand. J. Work, Environ. Health 36 (2), 121-133. https://doi.org/10.2307/40967838

Siegrist, J., Rödel, A., 2006. Work stress and health risk behavior. Scand. J. Work, Environ. Health 32 (6), 473-481. https://doi.org/10.5271/sjweh.1052

Silla, I., Gamero, N., 2014. Shared time pressure at work and its health-related outcomes: job satisfaction as a mediator. Eur. J. Work Organ. Psychol. 23 (3), 405-418. https:// doi.org/10.1080/1359432X.2012.752898

Tiznado, I., Galilea, P., Delgado, F., Niehaus, M., 2014. Incentive schemes for bus drivers: the case of the public transit system in Santiago, Chile. Res. Transp. Econ. 48, 77-83. https://doi.org/10.1016/j.retrec.2014.09.034

Tse, J.L.M., Flin, R., Mearns, K., 2006. Bus driver well-being review: 50 years of research. Transp. Res. Part F: Traffic Psychol. Behav. 9 (2), 89-114. https://doi.org/10.1016/J. TRF.2005.10.002

Tse, J.L.M., Flin, R., Mearns, K., 2007. Facets of job effort in bus driver health: deconstructing "effort" in the effort-reward imbalance model. J. Occup. Health Psychol. 12 (1), 48-62. https://doi.org/10.1037/1076-8998.12.1.48

Useche, S.A., Cendales, B., Gómez, V., 2017. Measuring fatigue and its associations with 
job stress, health and traffic accidents in professional drivers: the case of BRT operators. EC Neurol. 4 (4), 103-118.

Useche, S.A., Gómez Ortiz, V., Cendales, B.E., 2017. Stress-related psychosocial factors at work, fatigue, and risky driving behavior in bus rapid transport (BRT) drivers. Accid. Anal. Prev. 104, 106-114. https://doi.org/10.1016/j.aap.2017.04.023

Ward, N.J., Gorjestani, A., Shankwitz, C., Donath, M., Boer, E., de Waard, D., 2003. BusRapid Transit Lane Assist Technology Systems, Volume 2: Bus Driver Stress WhileOperating in Narrow Dedicated Bus Shoulders: A Pilot Study. Transportation Research Record.

Ward, N.J., Shankwitz, C., Gorgestani, A., Donath, M., de Waard, D., Boer, E.R., 2006. An evaluation of a lane support system for bus rapid transit on narrow shoulders and the relation to bus driver mental workload. Ergonomics 49 (9), 832-859.

Wirasinghe, S.C., Kattan, L., Rahman, M.M., Hubbell, J., Thilakaratne, R., Anowar, S., 2013. Bus rapid transit - a review. Int. J Urban Sci. 17 (1), 1-31. https://doi.org/10. 1080/12265934.2013.777514

Zimmerman, S.L., Levinson, H., 2004. Vehicle selection for BRT: issues and options. J. Public Transp. 7 (1), 83-103. https://doi.org/10.5038/2375-0901.7.1.5
Zuraida, R., K.G. Ayu, C.N. Septivani, and H. Iridiastadi. 2016. Research on BRT driver jakarta fatigue evaluation. In: Proceedings of the 2016 International Conference on Industrial Engineering and Operations Management, Kuala Lumpur, Malaysia.

Seyed Alireza Samerei is a Ph.D. candidate in the School of Civil Engineering, College of Engineering, at the University of Tehran. His research interests include traffic safety analysis, data mining techniques, and human factors in traffic engineering.

Kayvan Aghabayk earned his Ph.D. from Monash University, Australia. He is working now as an assistant professor in the School of Civil Engineering, College of Engineering, at the University of Tehran. His research interests include road safety engineering, vehicle collision research, and traffic engineering.

Alireza Soltani is a master's student in the School of Civil Engineering, College of Engineering, at the University of Tehran. 